\title{
An improved medium for isolation of Streptococcus mutans
}

\author{
W. G. WADE, M. J. ALDRED and D. M. WALKER \\ Department of Oral Medicine and Oral Pathology, Dental School, University of Wales College of Medicine, \\ Heath Park, Cardiff, Wales
}

\begin{abstract}
Summary. A medium based upon tryptone, yeast extract, cystine (TYC) agar and incorporating bacitracin and sucrose has been evaluated for selective isolation of Streptococcus mutans. The effect of varying the concentrations of sucrose and bacitracin on the recovery of two standard strains was investigated. Growth of $S$. mutans NCTC 10449 was significantly inhibited by increasing concentrations of sucrose but was not affected by bacitracin; the reverse was seen with $S$. sobrinus strain 6715 . The best compromise between recovery of the streptococci and growth of other organisms was obtained with a final sucrose concentration of $20 \%$ and bacitracin 0.2 units $/ \mathrm{ml}$. In comparison with three other selective media, this medium gave the highest recovery rate of standard strains, indicating that it is superior to mitis-salivarius bacitracin (MSB) agar for the recovery of $S$. mutans from saliva.
\end{abstract}

\section{Introduction}

There is considerable evidence incriminating Streptococcus mutans as the most important organism in the initiation of dental caries (McGhee and Michalek, 1981). The attention focussed on $S$. mutans in studies on the epidemiology and aetiology of caries, and the fact that this organism constitutes a relatively small proportion of dental plaque and salivary flora, has led to the development of many selective media for its isolation. These include a medium similar to mitis-salivarius (MS) agar containing a sulphonamide (Carlsson, 1967); mitis-salivarius-40\% sucrose (MS40S) agar (Ikeda and Sandham, 1972a); mitis-salivarius-sucrose-bacitracin (MSB) agar (Gold et al., 1973); mannitol-sorbitol-fuchsin-azide (MSFA) agar (Linke, 1977); and glucose-sucrose-telluritebacitracin (GSTB) agar (Tanzer et al., 1983).

The shortcomings of these media prompted the formulation of a medium based on tryptone, yeast extract, cystine (TYC) agar (de Stoppelaar, 1971) with the addition of sucrose and bacitracin (Van Palenstein Helderman et al., 1983; Wade et al., 1983). The effects of varying the concentration of sucrose and bacitracin on the recovery of two standard strains of $S$. mutans and on the numbers of contaminating organisms have been investigated and this new medium (TYCSB) compared to MSB, MSFA and GSTB.

Received 15 Dec. 1985; accepted 16 Jan. 1986.

\section{Materials and methods}

\section{Bacterial strains}

The standard strains employed in the study were $S$. mutans NCTC 10449 (serotype c) and S. sobrinus strain 6715 (S. mutans serotype d/g).

\section{Saliva samples}

Whole unstimulated saliva was collected from 20 randomly selected adult dentate subjects.

Effect of different concentrations of sucrose and bacitracin in TYC agar on recovery of $S$. mutans

Sucrose was added to TYC agar before autoclaving to give final concentrations of 10,20 and $30 \% \mathrm{w} / \mathrm{v}$. When the agar had cooled to $50^{\circ} \mathrm{C}$, bacitracin was added to give concentrations of $0 \cdot 1,0 \cdot 2$ and $0 \cdot 3$ units $/ \mathrm{ml}$.

Suspensions of $S$. mutans NCTC 10449 and $S$. sobrinus strain 6715 were made from 48 -h anaerobic plates in phosphate-buffered saline (PBS) and disaggregated by vortex mixing for $30 \mathrm{~s}$ and passage five times through a 25-gauge needle (Adams et al., 1982). Ten-fold dilutions were then prepared in PBS and $0.1 \mathrm{ml}$ of the $10^{3}, 10^{4}$ and $10^{5}$ dilutions spread in triplicate on blood agar, TYC agar and the TYC agar containing different combinations of sucrose and bacitracin. The plates were incubated anaerobically for $48 \mathrm{~h}$ at $37^{\circ} \mathrm{C}$. Plates with colony counts between 30 and 300 were selected. The result for each combination was expressed as a percentage of the 
count on blood agar and the effects of sucrose and bacitracin assessed statistically by analysis of variance.

Effect of different concentrations of sucrose and bacitracin on the numbers of contaminants growing on supplemented TYC plates inoculated with saliva

Concentrations of sucrose and bacitracin added to TYC agar were used as described above. Five saliva samples were disaggregated by passage through a 25 gauge needle and a $10^{2}$ dilution in PBS prepared; $0.1 \mathrm{ml}$ of each sample was plated on to each of the combinations in duplicate. The plates were incubated anaerobically for $48 \mathrm{~h}$ at $37 \mathrm{C}$. After incubation the plates were examined and the number of organisms other than $S$. mutans assessed. The density of growth was scored semiquantitatively: " 0 " indicated no contaminating organisms and "3" a "lawn" of contaminants.

The recovery of standard strains of $S$. mutans on TYC agar containing sucrose $20 \%$ and bacitracin 0.2 units $\mathrm{ml}$ compared to that on other selective media

The recovery of S. mutans on TYC agar containing bacitracin 0.2 units $/ \mathrm{ml}$ and supplemented with sucrose at a final concentration of $20 \%$ was compared with that on three other selective media-MSB (Gold et al., 1973), MSFA (Linke, 1977) and GSTB (Tanzer et al., 1983). Suspensions of S. mutans and S. sobrinus were prepared in PBS and the media inoculated and incubated as described above.

Recovery of S. mutans from saliva on TYC agar containing sucrose $20 \%$ and bacitracin 0.2 units/ml and $M S B$

Twenty saliva samples were processed as before and $0.1 \mathrm{ml}$ of $10^{3} \cdot 10^{2}$ and $10^{3}$ dilutions plated on TYC agar containing sucrose $20 \%$ and bacitracin 0.2 units $/ \mathrm{ml}$ and on MSB in triplicate. Plates were incubated anaerobically for $48 \mathrm{~h}$ at $37 \mathrm{C}$ when colonies whose morphology was typical of $S$. mutans were counted on appropriate plates. The results obtained with the two media were compared statistically by a paired $t$ test.

\section{Results}

Table I shows the recoveries of $S$. mutans NCTC 10449 and $S$, sohrinus strain 6715 on TYC and blood agar. The recovery of each strain on the selective medium exceeded $90 \%$ of that on blood agar.

Table Il shows the effect of the sucrose and bacitracin supplements in the TYC agar on the percentage recoveries of the two strains. For $S$. mutans the recovery varied from $65 \%$ (bacitracin 0.1 units $/ \mathrm{ml}$,
Table I. Recovery of $S$. mutans NCTC 10449 and $S$. sobrinus strain 6715 on TYC agar and blood agar

\begin{tabular}{|c|c|c|c|}
\hline \multirow[b]{2}{*}{ Species } & \multicolumn{2}{|c|}{ Number of colonies on } & \multirow{2}{*}{$\begin{array}{l}\text { Percentage } \\
\text { recovery } \\
\text { on TYC }\end{array}$} \\
\hline & $\begin{array}{l}\text { Blood agar } \\
\quad(n=3)\end{array}$ & $\begin{array}{c}\text { TYC } \\
(n=3)\end{array}$ & \\
\hline S. mutans & 100 & 98 & 98 \\
\hline S. sobrinus & 250 & 233 & 93 \\
\hline
\end{tabular}

Table II. Recovery of $S$. mutans NCTC 10449 and S. sobrinus strain 6715 on TYC agar supplemented with different concentrations of sucrose and bacitracin and on blood agar

\begin{tabular}{lcccc} 
Species & $\begin{array}{c}\text { Bacitracin } \\
\text { concentra- } \\
\text { tion } \\
\text { (units/ml) }\end{array}$ & $\begin{array}{c}\text { Percentage of count on blood agar } \\
\text { at sucrose concentration }(\% \mathrm{w} / \mathrm{v})\end{array}$ \\
\hline S. mutans* & $0 \cdot 1$ & 10 & 20 & 30 \\
\hline S. sobrinust & $0 \cdot 2$ & 65 & 51 & 40 \\
& 0.3 & 55 & 56 & 42 \\
& $0 \cdot 1$ & 89 & 73 & 38 \\
& 0.2 & 78 & 73 & 67 \\
& 0.3 & 50 & 37 & 49 \\
\hline
\end{tabular}

${ }^{*} \mathrm{~F}$ values $\left(\mathrm{df_{1 }}=2, \mathrm{df}_{2}=4\right)$ : bacitracin $6.38(\mathrm{NS})$; sucrose 30.81 $(\mathrm{p}<0.01)$.

$+F$ values $\left(d f_{1}=2, d f_{2}=4\right)$ : bacitracin $28.01(p<0.05)$; sucrose $3 \cdot 55$ (NS).

sucrose $10 \%$ ) to $38 \%$ (bacitracin $0 \cdot 3$ units $/ \mathrm{ml}$, sucrose $30 \%$ ), and for $S$. sobrinus from $89 \%$ (bacitracin 0.1 units $/ \mathrm{ml}$, sucrose $10 \%$ ) to $37 \%$ (bacitracin 0.3 units $/ \mathrm{ml}$, sucrose $20 \%$ ). Sucrose had a significant inhibitory effect on $S$. mutans but not on $S$ sobrinus. The converse was true for bacitracin.

The five saliva samples varied widely in the degree of growth of contaminants (table III). For example, sample $\mathrm{C}$ showed no growth on any of the plates, whereas sample $E$ gave a score of at least 2 on all plates. Inhibition of contaminants was observed with increasing concentrations of sucrose, while bacitracin appeared to have only a negligible effect.

The recovery of $S$. mutans on the four selective media is shown in table IV. The best recoveries were with GSTB (64\%) and TYCSB (60\%); MSB gave $46 \%$ recovery but MSFA did not allow growth of this organism at all. TYCSB gave the best recovery of $S$. sobrinus $(73 \%)$, followed by MSFA $(70 \%)$ and GSTB $(63 \%)$. MSB gave only $11 \%$ recovery. The recovery of $S$. mutans from 20 saliva samples with TYCSB and MSB is shown in table V. 
Table III. Growth of organisms other than S. mutans on supplemented TYC plates

\begin{tabular}{|c|c|c|c|c|}
\hline \multirow{2}{*}{$\begin{array}{l}\text { Saliva } \\
\text { sample }\end{array}$} & \multirow{2}{*}{$\begin{array}{c}\text { Bacitracin } \\
\text { concentra- } \\
\text { tion } \\
\text { (units } / \mathrm{ml} \text { ) }\end{array}$} & \multicolumn{3}{|c|}{$\begin{array}{c}\text { Growth* of other species } \\
\text { at sucrose concentration } \\
(\% \mathrm{w} / \mathrm{v})\end{array}$} \\
\hline & & 10 & 20 & 30 \\
\hline $\mathrm{A}$ & $\begin{array}{l}0 \cdot 1 \\
0 \cdot 2 \\
0 \cdot 3\end{array}$ & $\begin{array}{l}3 \\
3 \\
2\end{array}$ & $\begin{array}{l}1 \\
1 \\
1\end{array}$ & $\begin{array}{l}0 \\
0 \\
0\end{array}$ \\
\hline B & $\begin{array}{l}0 \cdot 1 \\
0 \cdot 2 \\
0 \cdot 3\end{array}$ & $\begin{array}{l}1 \\
0 \\
0\end{array}$ & $\begin{array}{l}0 \\
0 \\
0\end{array}$ & $\begin{array}{l}0 \\
0 \\
0\end{array}$ \\
\hline $\mathrm{C}$ & $\begin{array}{l}0 \cdot 1 \\
0 \cdot 2 \\
0 \cdot 3\end{array}$ & $\begin{array}{l}0 \\
0 \\
0\end{array}$ & $\begin{array}{l}0 \\
0 \\
0\end{array}$ & $\begin{array}{l}0 \\
0 \\
0\end{array}$ \\
\hline $\mathrm{D}$ & $\begin{array}{l}0 \cdot 1 \\
0 \cdot 2 \\
0 \cdot 3\end{array}$ & $\begin{array}{l}2 \\
2 \\
2\end{array}$ & $\begin{array}{l}1 \\
1 \\
1\end{array}$ & $\begin{array}{l}0 \\
0 \\
0\end{array}$ \\
\hline $\mathrm{E}$ & $\begin{array}{l}0 \cdot 1 \\
0 \cdot 2 \\
0 \cdot 3\end{array}$ & $\begin{array}{l}3 \\
2 \\
3\end{array}$ & $\begin{array}{l}3 \\
2 \\
2\end{array}$ & $\begin{array}{l}2 \\
2 \\
2\end{array}$ \\
\hline
\end{tabular}

*3= confluent growth; $2=$ intermediate; $1=$ slight $; 0=$ no growth.

Table IV. Recovery of $S$. mutans and $S$. sobrinus on MSB, MSFA, GSTB, TYCSB and blood agar

\begin{tabular}{lcccc}
\hline Medium & $\begin{array}{c}\text { Mean number of colonies } \\
\text { (on three plates) of }\end{array}$ & $\begin{array}{c}\text { Percentage of count } \\
\text { on blood agar }\end{array}$ \\
\cline { 2 - 5 } & S. mutans & S. sobrinus & S. mutans & S. sobrinus \\
\hline Blood agar & 320 & 149 & 100 & 100 \\
MSB & 147 & 16 & 46 & 11 \\
MSFA & no growth & 105 & - & 70 \\
GSTB & 205 & 94 & 64 & 63 \\
TYCSB & 193 & 108 & 60 & 73 \\
\hline
\end{tabular}

Because of the wide variation in the counts in different individuals, it was first necessary to normalise the distribution of the data to perform statistical analyses. A logarithmic transformation was used and was followed by a paired $t$ test. Sample 13 yielded no $S$. mutans from a $10^{1}$ dilution and was discarded, thus reducing $\mathrm{n}$ to 19.

TYCSB gave a significantly higher recovery of $S$. mutans than MSB $(\mathrm{p}<0 \cdot 05)$.

\section{Discussion}

Gold et al. (1973) devised a medium selective for $S$. mutans consisting of mitis-salivarius agar with
Table V. Isolation of $S$. mutans from saliva on TYCSB and MSB

\begin{tabular}{|c|c|c|c|c|}
\hline \multirow[b]{2}{*}{$\begin{array}{c}\text { Saliva } \\
\text { sample no. }\end{array}$} & \multicolumn{4}{|c|}{ Viable count $(\mathrm{cfu} / \mathrm{ml})$ of $S$. mutans on } \\
\hline & $\begin{array}{c}\text { TYCSB } \\
\left(10^{4}\right)\end{array}$ & $\begin{array}{l}\text { MSB } \\
\left(10^{4}\right)\end{array}$ & $\begin{array}{c}\log _{10} \text { TYCSB } \\
\text { count }\left(10^{4}\right)\end{array}$ & $\begin{array}{l}\log _{10} \text { MSB } \\
\text { count }\left(10^{4}\right)\end{array}$ \\
\hline 1 & 19.0 & $27 \cdot 0$ & $1 \cdot 28$ & 1.43 \\
\hline 2 & $8 \cdot 7$ & 6.8 & 0.94 & 0.83 \\
\hline 3 & $220 \cdot 0$ & $150 \cdot 5$ & $2 \cdot 34$ & $2 \cdot 18$ \\
\hline 4 & $59 \cdot 0$ & $66 \cdot 0$ & $1 \cdot 77$ & 1.82 \\
\hline 5 & $9 \cdot 2$ & $7 \cdot 8$ & 0.96 & 0.89 \\
\hline 6 & $32 \cdot 1$ & $20 \cdot 8$ & $1 \cdot 51$ & $1 \cdot 32$ \\
\hline 7 & 8.6 & $5 \cdot 7$ & 0.93 & 0.76 \\
\hline 8 & $19 \cdot 3$ & $12 \cdot 0$ & 1.29 & 1.08 \\
\hline 9 & $8 \cdot 5$ & $5 \cdot 6$ & 0.93 & 0.75 \\
\hline 10 & 6.8 & $6 \cdot 5$ & 0.83 & 0.81 \\
\hline 11 & $11 \cdot 4$ & $10 \cdot 5$ & 1.06 & 1.02 \\
\hline 12 & $1 \cdot 1$ & $1 \cdot 1$ & 0.04 & $0 \cdot 04$ \\
\hline 14 & $26 \cdot 7$ & $23 \cdot 9$ & 1.43 & 1.38 \\
\hline 15 & $24 \cdot 8$ & $15 \cdot 5$ & $1 \cdot 39$ & $1 \cdot 19$ \\
\hline 16 & $13 \cdot 5$ & $3 \cdot 6$ & $1 \cdot 13$ & 0.56 \\
\hline 17 & $65 \cdot 3$ & $61 \cdot 7$ & 1.81 & 1.79 \\
\hline 18 & $24 \cdot 0$ & $22 \cdot 3$ & $1 \cdot 38$ & $1 \cdot 35$ \\
\hline 19 & 95.0 & $72 \cdot 0$ & 1.98 & $1 \cdot 86$ \\
\hline 20 & $41 \cdot 0$ & $52 \cdot 0$ & 1.61 & 1.72 \\
\hline
\end{tabular}

$\log _{10}$ TYCSB count vs. $\log _{10}$ MSB count, $t=2 \cdot 738, p<0.05$.

bacitracin $0 \cdot 2$ units $/ \mathrm{ml}$ and a sucrose concentration of $20 \%$. These workers reported undiminished recovery of $S$. mutans and good suppression of other organisms. However, it was subsequently reported that serotype-a strains were inhibited completely and that the various manufacturers' preparations of the base medium yielded markedly different recoveries (Emilson and Bratthall, 1976; Liljemark et al., 1976; Staat, 1976). In the present investigation, it was therefore decided to add various concentrations of sucrose and bacitracin to a different base medium-TYC - as a new selective medium for the isolation of $S$. mutans.

Before evaluating the effect of these additives to TYC medium, the recovery of $S$. mutans on TYC agar alone was compared to that on blood agar. Representatives of serotypes c of $S$. mutans (NCTC 10449) and d/g of $S$. sobrinus (6715) were chosen for this comparison because these serotypes are the ones most commonly found in Europe and in the USA (Bratthall, 1972; Shklair and Keene, 1974). The percentage recovery of $S$. mutans and of $S$. sobrinus on TYC was respectively $98 \%$ and $93 \%$ of that on blood agar (table I).

The results obtained with different combinations of concentrations of sucrose and bacitracin indicated that recovery of $S$. mutans was significantly inhibited by a $30 \%$ sucrose concentration whereas 
bacitracin had little effect. $S$. sohrinus exhibited the reverse effect. being inhibited by bacitracin $0 \cdot 3$ units $\mathrm{ml}$ but not significantly by sucrose. There was no difference in the recovery of either organism with a concentration of bacitracin between 0.1 and 0.2 units $/ \mathrm{ml}$ and the latter concentration was adopted in the further experiments.

At the concentrations tested, sucrose had a significant inhibitory effect on the numbers of organisms other than S. mutans, but bacitracin did not. Therefore, the higher the sucrose concentration employed, the fewer contaminants would be expected. However, as already mentioned, high sucrose concentrations also inhibited the recovery of a serotype-c strain.

Thus the optimal concentrations of sucrose and bacitracin proved to be $20 \%$ and 0.2 units $/ \mathrm{ml}$ respectively for the purpose of achieving maximum recovery of the $S$. mutans while suppressing the growth of other organisms.

Other selective media have been created for the isolation of $S$. mutans in addition to differential media. notably MM10 (Syed and Loesche. 1972) and BCY (Ikeda and Sandham, 1972b). These did not inhibit other organisms, but allowed the detection and enumeration of $S$. mutans.

None of the media previously developed for the selective isolation of $S$. mutans has proved ideal. Carlsson (1967) utilised the sulphonamide resistance of S. mutans and susceptibility of the other oral streptococcal species and incorporated sulphadimidine $1 \mathrm{~g} / \mathrm{L}$ into a base medium similar to mitissalivarius agar. This proved selective for the isolation of $S$. mutans from unspecified samples from the oral cavity, although contaminants amounted to approximately $5 \%$ of the total count on ordinary mitis-salivarius agar. The total streptococcal count in saliva is usually about 1000 times greater than the $S$. mutans count and such a degree of contamination is unacceptable.

The medium of Ikeda and Sandham (1972a), containing $40 \%$ sucrose, is also selective for $S$.

\section{REFERENCES}

Adams D. Rawle L. White S 1982 Quantitative methods used to assess bacteria in plaque. In: Frank R H. Leach S A (eds) Surface and colloid phenomena in the oral cavity: methodological aspects. IRL Press, London, pp 213-225.

Bratthall D 1972 Demonstration of Streptococcus mutans strains in some selected areas of the world. Odontologisk Rerr 23:401 410

Carlsson J 1967 A medium for isolation of Streptococcus mutans. Archives of Oral Biology 12:1657 1658. mutans, but gave only $37 \%$ recovery of the organism compared with the basic mitis-salivarius agar. This suggests that a sucrose concentration as high as $40 \%$ is partially inhibitory to S. mutans, a finding confirmed by Gold et al. (1973). Gold et al. (1973) found that the degree of inhibition varied markedly with the strain studied, and this has also been confirmed in the present study.

Three other media were compared with TYCSB for their ability to recover $S$. mutans and $S$. sobrinus. The media chosen were MSB (Gold et al., 1973). almost universally adopted for the selective isolation of $S$. mutans, Linke's (1977) MSFA, and GSTB as described by Tanzer et al. (1983).

Optimal recovery of $S$. mutans was obtained on GSTB and TYCSB (64\% and $60 \%$ respectively). The recovery was only $46 \%$ on MSB and there was no growth on MSFA. This finding was confirmed on repeated testing. This is in contrast to Linke's original report (1977) where this strain was found to grow well, producing blue-purple silky colonies. However, Linke (1977) incubated the plates aerobically for 10 days whereas in this study they were incubated anaerobically for $48 \mathrm{~h}$.

In contrast, MSFA proved effective in recovering S. sobrinus $(70 \%)$ and TYCSB proved equally good $(73 \%)$. GSTB gave a $63 \%$ recovery but MSB only $11 \%$.

TYCSB therefore appears to be superior to the other media tested, although GSTB deserves further study. Linke's medium (1977) proved unreliable and also allowed growth of other mannitolutilising organisms such as enterococci and staphylococci. TYCSB allows a more complete recovery of $S$. mutans than MSB and thus might be expected to detect these organisms in samples when present in numbers undetectable by MSB.

The assistance of Dr R. G. Newcombe, Department of Medical Statistics, with the statistical analysis is gratefully acknowledged. This project was supported by the Welsh Scheme for the Development of Health and Social Research. de Stoppelaar J D 1971 Streptococcus mutans, Streptococcus sanguis and dental caries. Thesis, Rijksuniversiteit, Utrecht.

Emilson C G. Bratthall D 1976 Growth of Streptococcus mutans on various selective media. Journal of Clinical Microbiology 4:95-98.

Gold O G, Jordon H V, Van Houte J 1973 A selective medium for Streptococcus mutans. Archives of Oral Biology 18: 1357-1364.

Ikeda T, Sandham H J $1972 a$ A high-sucrose medium for the identification of Streptococcus mulans. Archives of Oral Biology 17:781-783. 
Ikeda T, Sandham H J $1972 b$ A medium for the recognition and enumeration of Streptococcus mutans. Archives of Oral Biology 17:601-604.

Liljemark W F, Okrent D H, Bloomquist C G 1976 Differential recovery of Streptococcus mutans from various mitissalivarius agar preparations. Journal of Clinical Microbio$\log y$ 4:108-109.

Linke H A B 1977 New medium for the isolation of Streptococcus mutans and its differentiation from other oral streptococci. Journal of Clinical Microbiology 5:604-609.

McGhee J R, Michalek S M 1981 Immunobiology of dental caries: microbial aspects and local immunity. Annual $R e$ view of Microbiology 35:595-638.

Shklair I L, Keene H J 1974 A biochemical scheme for the separation of the five varieties of Streptococcus mutans. Archives of Oral Biology 19:1079-1081.
Staat R H 1976 Inhibition of Streptococcus mutans strains by different mitis-salivarius agar preparations. Journal of Clinical Microbiology 3:378-380.

Syed S A, Loesche W J 1972 Survival of human dental plaque flora in various transport media. Applied Microbiology 24: $638-644$.

Tanzer J M, Borjesson A C, Kurasz A, Laskoski L. Testa M, Krasse B 1983 GSTB, an alternative to MSB agar. Journal of Dental Research 62:241. (Abstract).

Van Palenstein Helderman W H, ljsseldijk M, Huis in't Veld J H J 1983 A selective medium for the two major subgroups of the bacterium Streptococcus mutans isolated from human dental plaque and saliva. Archives of Oral Biology 28:599-603.

Wade W G, Llewllyn D R, Walker D M, Aldred M J 1983 A new medium for the isolation of Streptococcus mutans. Journal of Dental Research 62:420 (Abstract). 